\title{
Lior-serotype variants in Campylobacter isolates from the same stool sample
}

\author{
B. ZÖLLNER* and H.-H. WUTHE \\ Institut für Medizinische Mikrobiologie, 2300 Kiel, Germany
}

\begin{abstract}
Summary. Campylobacter strains isolated from the same stool sample were characterised by determination of biochemical properties and both heat-labile (Lior) and heat-stable (Lauwers) serotypes. In six of 60 campylobacter-infected stools, two or three strains differing in Lior-serotype were isolated from the same stool. In four of these six cases, the isolates with different Lior-serotypes showed identical biochemical reactions and identical heat-stable antigenic patterns. A predominant Lior-serotype was not detected among them but Lauwersantigens $\mathrm{O}: 3, \mathrm{O}: 14$ and $\mathrm{O}: 16$ were found in isolates from three of the six stool samples. Moreover, the isolates were identified as $C$. coli in $76.5 \%$ of the stool samples $(\mathrm{p}<0.05)$. We believe that variation in heat-labile antigens occurs in vivo and might be associated particularly with certain heat-stable serotypes of $C$. coli.
\end{abstract}

\section{Introduction}

Serological analysis of Campylobacter isolates is important in epidemiological studies. Two different methods of serotyping are widely used: the slideagglutination technique with living bacteria according to Lior et al. ${ }^{1}$ and the passive haemagglutination

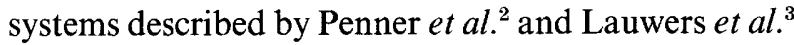
While the Lior scheme is based upon heat-labile antigens (most probably campylobacter flagella), passive haemagglutination detects heat-stable antigens shown to be somatic lipopolysaccharide (LPS) components. ${ }^{4}$ Several authors ${ }^{5-8}$ have described mixed infections with different serotypes of Campylobacter strains in the same stool sample. In some cases, the isolates differed also in biochemical reactions such as hippurate hydrolysis. To analyse mixed infections in more detail, we applied both the Lior and the Lauwers serotyping schemes, as well as extended biochemical tests, to several Campylobacter isolates from single stool samples from 60 patients.

\section{Materials and methods}

Strains were isolated from 60 patients with campylobacter infections. Faecal samples were plated on to blood agar and incubated in $\mathrm{CO}_{2} 10 \%$ at $37^{\circ} \mathrm{C}$. Three different-sized colonies were subcultured from each specimen on the same plate. The biochemical properties tested for each isolate were hippurate

Received 20 Feb. 1992; accepted 30 March 1992.

* Present address: Institut für Medizinische Mikrobiologie und Immunologie, Martinistr. 52, 2000 Hamburg, Germany. hydrolysis according to Harvey, ${ }^{9}$ DNAase-activity on methyl green $\operatorname{agar}^{10}$ and toluidine blue-DNA agar, ${ }^{11}$ resistance to nalidixic acid, and, in some cases, the rapid formation of $\mathrm{H}_{2} \mathrm{~S}$ and tolerance to trimethylamine $\mathrm{N}$-oxide (TMAO) as described by Lior. ${ }^{10}$ Strains were examined for motility immediately after isolation to prevent change in or loss of flagella and then the Lior-serotype was determined with antisera obtained from Sopar Biochem, Brussels. The kit provides polyand monovalent antisera as well as highly specific, absorbed antisera used to confirm all serotypes. Strains were emulsified in a DNAase solution before determination of the serotype, to remove extracellular DNA which may be associated with slime. By that means, otherwise untypable strains could be serotyped. ${ }^{1}$ Subsequently, strains thought to be from mixed infections were lyophilised and serotyped according to Lauwers' scheme, as previously described. ${ }^{3}$ Strains were also subcultured up to 10 times alternately in liver-bouillon and on Mueller-Hinton-agar containing sheep blood $5 \%$. Afterwards the Lior-serotype was re-determined. The $\chi^{2}$-test was used for statistical analysis of results.

\section{Results}

Seventy-one different Campylobacter strains were isolated from the faeces samples from the 60 patients suffering from campylobacter infections; 33 $(46.5 \%)$ strains were identified as $C$. jejuni and 38 $(53.5 \%)$ as $C$. coli by hippurate hydrolysis. Two or three Campylobacter strains differing in biochemical reactions, resistance to nalidixic acid or Lior-serotype were detected in the stool of six patients (table). 
Table. Campylobacter isolates from six stools of patients with suspected mixed infection

\begin{tabular}{|c|c|c|c|}
\hline $\begin{array}{l}\text { Patient } \\
\text { no. }\end{array}$ & $\begin{array}{c}\text { Camplobacter } \\
\text { spp. }\end{array}$ & Lior-serotype & Lauwers-serotype \\
\hline \multirow[t]{2}{*}{1} & C.coli* & 1 & 3. 14.16 \\
\hline & C.coli & $\mathrm{NT}$ & 3.14 .16 \\
\hline \multirow[t]{3}{*}{2} & C.coli & 29,55 & 27 \\
\hline & C.coli & 55 & NT \\
\hline & C. coll & 29 & 27 \\
\hline \multirow[t]{3}{*}{3} & C. coti & $\mathrm{NT}$ & 2.36 \\
\hline & C.coli & $2 .[53]$ & 2,36 \\
\hline & C. coli & 2 & 2. 36 \\
\hline \multirow[t]{3}{*}{4} & C. coli & 4.21 & 1 \\
\hline & C.coli & {$[17] .21$} & 1 \\
\hline & C.coli & [4] & $i$ \\
\hline \multirow[t]{3}{*}{5} & C. colit & 2 & {$[3],[14], 16$} \\
\hline & C. ioli & 2 & 3,16 \\
\hline & C. jejuni & 7 & 3.14 .16 \\
\hline \multirow[t]{3}{*}{6} & C. iejmi & {$[44]$} & 3.16 .25 \\
\hline & C. iteikni & 19 & $3.16,25$ \\
\hline & C.jejuni & [9] & 3.16 .25 \\
\hline
\end{tabular}

[]. weak reaction with homologous. absorbed antiserum. NT. not typable

* Nalidixic acid-resistant Camplohacter strain: rapid $\mathrm{H}_{2} \mathrm{~S}$-test negative. no growth in the presence of TMAO."

Repeated subculturing of these strains did not alter the heat-labile antigenic pattern in any case. Four $(23.5 \%)$ of the 17 strains were identified as $C$. jejuni and 13 $(76.5 \%)$ as $C$. coli. For patients nos. 1 and 5 , the isolates differed not only in Lior-serotype but also in sensitivity to nalidixic acid (patient no. 1) and in the ability to hydrolyse hippurate (patient no. 5). A predominant Lior-serotype was not observed among the strains of the six patients. However, the isolates from four of the six patients were indistinguishable in any one patient when the somatic antigen was determined by passive haemagglutination. Patient no. 2 had one strain of C. coli serotype Lior 29, Lauwers 27 and another C. coli strain of serotype Lior 55, Lauwers not typable. Patient no. 5 had a Campylobacter strain of serotype Lior 7 and another strain of serotype Lior 2. Although these isolates also differed in their ability to hydrolyse hippurate, suggesting they were of different Campylobacter spp., their nearly identical $\mathrm{O}$ antigenic constellation is remarkable. Furthermore, it is interesting that Lauwers-serotypes $0: 3,0: 14$ and $O: 16$ were found in varying combinations in three of the six cases of suspected mixed infection.

\section{Discussion}

These resuls show that Campylobacter strains differing in Lior-serotype can be isolated from the same stool sample. These strains can have a common biochemical and, most remarkably, an identical heatstable $\mathrm{O}$-antigenic pattern. Two different theories might explain this phenomenon.

Firstly, Campllobacter strains with identical Oantigenic pattern might have different heat-labile antigens, a feature comparable to that in Salmonella spp. Additional biochemical differences (e.g., patient no. 5) or different resistance patterns (e.g., patient no. 1) among isolates would then support the diagnosis "mixed campylobacter infection". However, it is unlikely that two or even three strains with identical $\mathrm{O}$-antigenic serotypes are ingested by one patient.

Alternatively, it is possible that antigenic variation of a single strain could simulate a mixed infection. Antigenic variation in campylobacters has been described by several authors. Flagellar variations of $C$. coli were associated with reversible genomic rearrangements. ${ }^{12}$ Preston and Penner ${ }^{13}$ discussed antigenic variation of heat-stable LPS components as a cause of cross-reactions of $C$. jejuni serotypes $4,13,16$, 43 and 50 (according to Penner's scheme). Albert et $a l^{8}$ isolated Campylobacter strains with closely related heat-stable serotypes from a single patient and considered them to be host-induced antigenic variations. Recently, Mills et al. ${ }^{14}$ reported that changes in the somatic LPS-antigenic specificities of $C$. coli arose through laboratory manipulations involving longterm subculture.

Our results show that in a single stool sample, there may be Campylobacter strains with identical biochemical and LPS-antigenic pattern, but different heat-labile antigens. Because subculturing of isolates did not alter their heat-labile antigenic pattern and because there was only a short period between isolation of a strain and determination of its Lior-serotype, laboratoryinduced antigenic variation is unlikely to have occurred, although it cannot be excluded. If Lior-type antigenic variation did not occur in vitro, it must have developed in vivo. To our knowledge, our work is the first indication that there may be heat-labile antigenic variation in Campylobacter strains in vivo. This would have major epidemiological implications when serotyping of campylobacters is based on this antigen. It is interesting that Lauwers serotypes $O: 3,0: 14$ and $O: 16$ are apparently quite often associated with different heat-labile antigens. Moreover, the high proportion of $C$. coli in these cases is remarkable. We speculate that antigenic variation, perhaps due to genomic re-arrangements, might even influence the biochemical properties of a certain strain, so that, e.g., in patient no. 5 , the ability to hydrolyse hippurate is lost. Indeed, Totten et al. ${ }^{15}$ showed that nine $(20 \%)$ of 46 hippurate-negative Campylobacter strains were $C$. jejuni. Further studies, such as restriction endonuclease analysis. are now required to determine whether these phenomena are a common feature of thermophilic Campylobacter spp. or are restricted to certain serotypes. For precise epidemiological investigations it seems to be necessary to identify both heat-labile and heat-stable antigens of different colonies. This is very laborious but it helps to distinguish between true mixed infections and infections caused by antigenic variants of a single strain.

We thank S. Lauwers. Brussels, for serotyping the heat-stable antigens of the Campylobacter strains. 


\section{References}

1. Lior H, Woodward, DL, Edgar JA, Laroche LJ, Gill P Serotyping of Campylobacter jejuni by slide agglutination based on heat-labile antigenic factors. J Clin Microbiol 1982; 15: 761-768.

2. Penner JL, Hennessy JN, Congi RV. Serotyping of Campylobacter jejuni and Campylobacter coli on the basis of thermostable antigens. Eur J Clin Microbiol 1983; 2: 378-383.

3. Lauwers S, Vlaes L, Butzler JP. Campylobacter serotyping and epidemiology. Lancet 1981; 1 : 158-159.

4. Preston MA, Penner JL. Structural and antigenic properties of lipopolysaccharides from serotype reference strains of Campylobacter jejuni. Infect Immun 1987; 55: 1806-1812.

5. Figura N. Isolation of different species and/or serogroups of Campylobacter from the same stool sample. $J$ Infect Dis 1987; 155: 1345.

6. Lastovica AJ, Le Roux E, Penner JL. Mixed infections with different species and serotypes of Campylobacter. $J$ Infect Dis 1986; 154: 375.

7. Sjögren E, Ruiz-Palacios G, Kaijser B. Campylobacter jejuni isolations from Mexican and Swedish patients, with repeated symptomatic and/or asymptomatic diarrhoea episodes. Epidemiol Infect 1989; 102: 47-57.

8. Albert MJ, Leach A, Asche V, Hennessy J, Penner JL. Serotype distribution of Campylobacter jejuni and Campylobacter coli isolated from hospitalized patients with diarrhea in Central Australia. J Clin Microbiol 1992; 30: 207-210.

9. Harvey SM. Hippurate hydrolysis by Campylobacter fetus. $J$ Clin Microbiol 1980; 11: 435-437.

10. Lior H. New, extended biotyping scheme for Campylobacter jejuni, Campylobacter coli and "Campylobacter laridis". J Clin Microbiol 1984; 20: 636-640.

11. Lior H, Patel A. Improved toluidine blue-DNA agar for detection of DNA hydrolysis by campylobacters. $J$ Clin Microbiol 1987; 25: 2030-2031.

12. Guerry P, Logan SM, Trust TJ. Genomic rearrangements associated with antigenic variation in Campylobacter coli. $J$ Bacteriol 1988; 170: 316-319.

13. Preston MA, Penner JL. Characterization of cross-reacting serotypes of Campylobacter jejuni. Can J Microbiol 1989; 35: $265-273$.

14. Mills SD, Kurjanczyk LA, Shames B, Hennessy JN, Penner JL. Antigenic shifts in serotype determinants of Campylobacter coli are accompanied by changes in the chromosomal DNA restriction endonuclease digestion pattern. $J$ Med Microbiol 1991; 35: 168-173.

15. Totten PA, Patton CM, Tenover FC et al. Prevalence and characterization of hippurate-negative Campylobacter jejuni in King County, Washington. J Clin Microbiol 1987; 25: $1747-1752$. 